\title{
Analysis on the Vertical Greening Application in Restaurant Space
}

\author{
Tingting Tan \\ College of Art \\ Suzhou University \\ Suzhou, China
}

\begin{abstract}
Greening is a very important part of the restaurant space, if without greening, it will lack of vigor and vitality, due to space limitations for restaurant space and other issues, vertical greening increasingly applied to the restaurant. This article starts with the introduction of the characteristics of vertical greening, sort through the specific forms of vertical greening, through vertical greening 's aesthetic characteristics and examples to analyze the vertical greening application in restaurant space.
\end{abstract}

Keywords—vertical greening; restaurant space; ecology

\section{INTRODUCTION}

With the improvement of people's living standards, catering industry has been more and more developed, the decoration in restaurant space are increasingly focusing on ecological and human psychological needs, due to the space limitation and beauty demands of the restaurant space , coupled with the development of technology, vertical greening is becoming more and more common in restaurant space.

\section{THE FEATURES OF VERTICAL GREENING}

With the accelerating process of urbanization, people's awareness of the importance of greening is growing, normally the common greening are planted on land, vertical greening is different from the usual greening which are planted flat on the ground, it refers to the greening perpendicular to the ground and attached to the building surface or the vertical flower rack. In the past vine plants were the main plants for vertical greening to decorate the urban environment, due to land increasingly scarce and people's aesthetic demands increase, coupled with new greening technology development, now it can plant different plants which played a beautification function for indoor and outdoor environment and urban space. Indoor vertical greening can save space, adjust the temperature and other effects. Indoor vertical greening can save and beautification interior space more efficiently than the flat greening, so it is very worthy of study and thinking.

\section{THE SPECIFIC FORM OF COMMON INDOOR VERTICAL GREENING}

In the past, Vertical Greening are vine plants, first it grow slowly, the major factors for growth trend are uncertainty, the color is single and mostly are deciduous plants which is not suitable for indoor planting. With the development of the times, it derived a variety of indoor vertical greening forms:

\section{A. Dangling Flowerpot Style Greening}

This form is primitive indoor vertical greening, its planting form is not much difference than the ordinary indoor greening, sowed seeds in pots, mounted racks on the wall, and placed pots in the rack or dangling the pots with chains on the wall. Such Indoor vertical greening only slightly change the ordinary greening form, increase the indoor greening rate but not use much space also it is easy to manage with lower maintenance costs. [1]

\section{B. Green Wall}

As technology improved, so that the plant green wall can be used indoor and the choice of plant species is rich, you can design the plant green wall with different colors and different forms.

1) Modular Wall greening: Modular wall greening is a form uses geometric modular to plant plants so to achieve wall greening. Modules are several parts with different forms combined together, usually it need to be customized based on the requirements, after several months of foster conservation, and then shipped to site for installation. [2] It applies to all types of plants, skeleton fixed on the wall, and with automatic drip irrigation system. But it has large thickness and higher price.

2) Paving type wall greening: Paving type wall greening is also called wall planting which is a plane planting system directly paving plant nutrient substrate and the plants on the wall or use spraying technology on the wall to form a planting system. [3] It applies to all types of plants, and it is thin, long lifetime, but the price is high.

\section{AESTHETIC FeAtURES OF VERTICAL GREENING IN RESTAURANT SPACE}

As an indoor decoration form of restaurant space, vertical greening's aesthetic features can bring unique experience to consumers. 


\section{A. Color}

Color, as one of the elements with most visual information transmission function, it can bring directly feelings to people and also it is the most directly performance mode for the vertical greening. The vertical greening and its bright green color, gives a sense of natural health. Plants are decorations with vitality, in different seasons will show different colors. Take green as the main color and decorate with dark and light green colors plants and with different plants combinations based on the indoor environment, the different color and shades of color matching can give a strong sense of beauty, also it could promote the appetite.

\section{B. Morphology}

One of the characteristics of natural plants is it has their own morphology, different size and shape of plant leaves and different lengths of stems can produce different results in the vertical green wall design. During the design process of plant green wall, it is necessary to pay attention to the unity of the composition, but also consider changes in rhythm and cadence, the level density, the volume size should also be considered so that the viewers with visual movement can experience different scenes and increased its interest. [4]

\section{Texture}

Stems and leaves of different plants have different textures, some plant leaves smooth, some rough, some in between. Different texture reflects different degrees of light. In the restaurant space use large area of plant with smooth leaf will bring a fresh sense of permeability. Because of its different texture and size, plants can be divided into suitable for distance watch and suitable for close-up watch 2 types. Vertical green wall at the entrance can mainly use plants suitable for distance watch and with big leaves and supplemented by small plants, vertical greening next to the table can use the exquisite compact plants suitable for close-up watch.

\section{Advantage of Vertical GREENING IN RESTAURANT SPACE}

People living in the city regardless of when and where they are, all look forward to the ecological environment and the contact with nature. It is the same in restaurant, the greening added in the restaurant space can bring people comfortable experience and to be closer to nature. Normally the restaurant greening is plane greening which planted in flowerpots, but space limitation of the restaurant sometimes result in insufficient greening, but vertical greening is a good solution for this problem.

\section{A. Beautify Restaurant Space Environment}

Different plant species have different colors and patterns, applied to the restaurant space mix with the interior decoration can create different effects. In light-colored restaurant space, vertical greening, can make the environment more fresh and bright; and in the dark, masonry textured restaurant space, vertical greening can increase the sense of simple in space and also closer to the nature. For some restaurants, we also designed their outside wall as a vertical green wall and put the name of the restaurant on it, illuminated by spotlights, so that consumers will be attracted before entering the restaurant. For example, the grandma's restaurant Suzhou Yuanrong branch "Fig. 1".

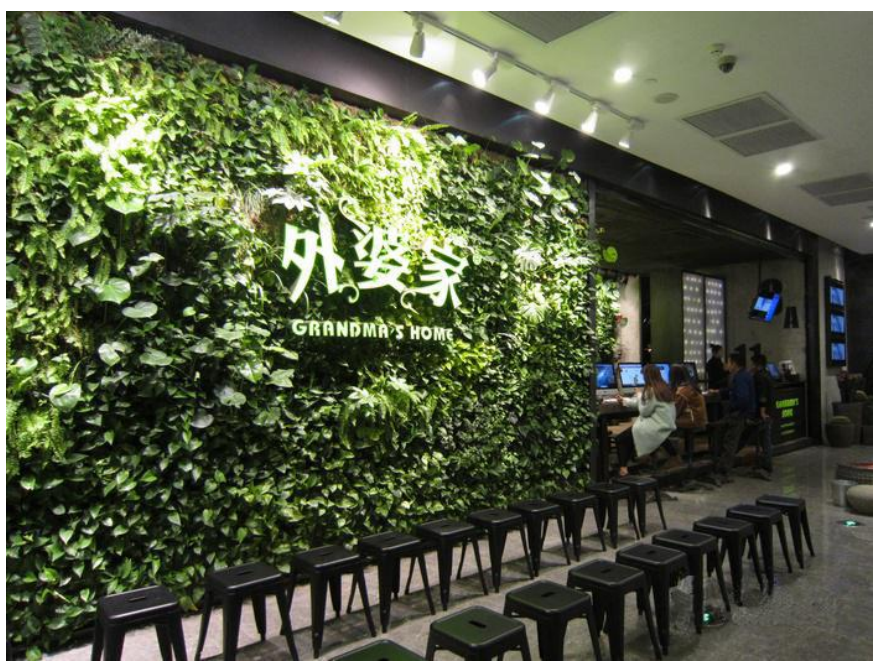

Fig. 1. The grandma's restaurant Suzhou Yuanrong branch

\section{B. Increase Ecological in Restaurant Space}

Through photosynthesis, green plants will absorb carbon dioxide and release oxygen, some plants can absorb undesirable gases, help clean indoor air, and by transpiration can adjust the indoor temperature and humidity. Some plants also secrete a special smell to make people feel physical pleasure and relaxation. In plants selection, we should give full consideration of the local climatope, choose the plants that most suitable for local temperature. As plants has the function to beautify the indoor environment, so we need to choose evergreen plants, some restaurant's main light source is lamplight and the natural light is inadequate, so we need to choose shade-tolerant plants. The smell in restaurant would be more complicated, plants can purify the indoor air and release fresh air. There are the features of the plants which suitable for indoor green wal in "Table I". 
TABLE I. THE FEATURES OF THE PLANTS WHICH SUITABLE FOR INDOOR GREEN WALL

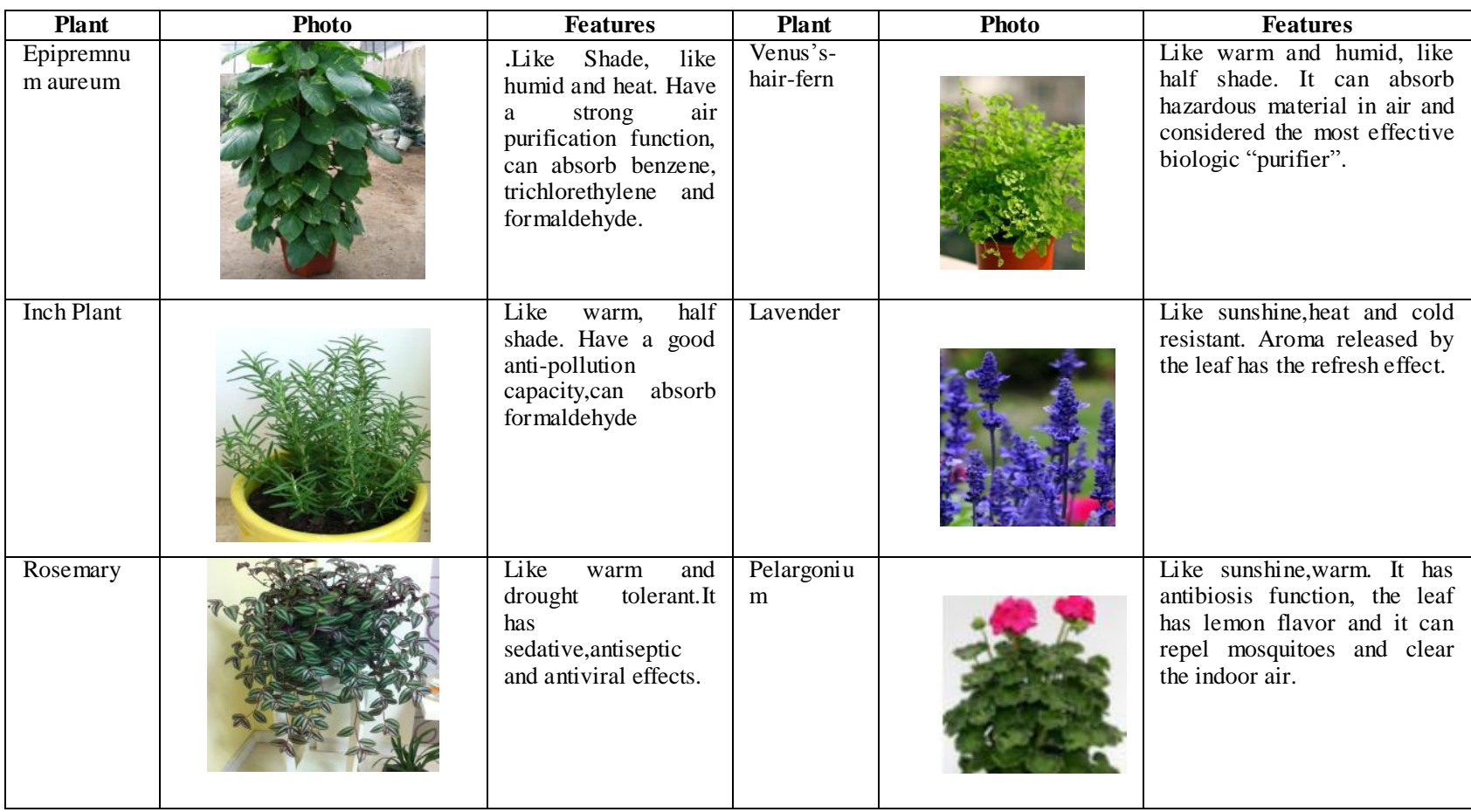

\section{Play the Role of Distributary and Shelter}

Vertical Greening attaches to the wall or flower stand so it can planning the interior flow lines in restaurant space and make the regional segmentation, as shown in "Fig. 2". Vertical green bookshelf in a cafe shop in Beijing, it combines ecology and function together so it has decorative effect and also has the effect of dividing space. The hollow design focus on customers' privacy while increasing the permeability of space, it is quiet but not boring.

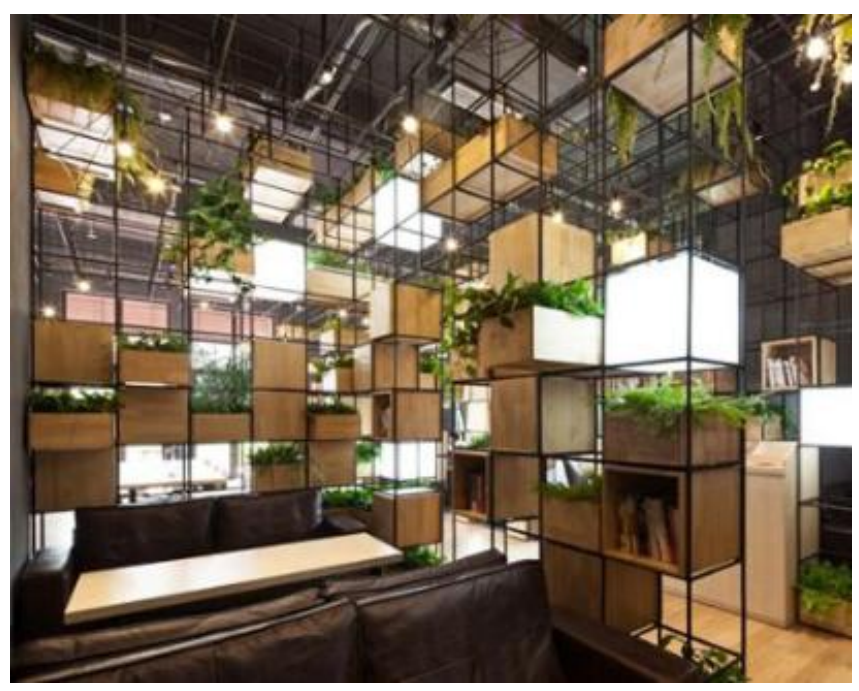

Fig. 2. Vertical green bookshelf in a cafe shop in Beijing

\section{Application of Simulation Plant Wall in the RESTAURANT SPACE}

Although vertical greening has many advantages, but there are also some disadvantages. Plant wall not only has a high installation cost, and because the wall is a living plant, so it has high requirements for environment, light, moderate and other factors will affect the health of the plant. The smell of some plants will attract mosquitoes, in summer the front vertical greening is easier to attract mosquitoes. New and replacement of life will have to produce fallen leaves, and compare with plane greening, the maintenance process for vertical greening is more complex and its technical content is also higher, so the professional conservation cot will be high. Plant wall become popular in restaurant not just because the ecological drive for fresh air and soothing factor secretion, but also showed people longing for nature. Due to cost, maintenance problems, a new simulation plants wall is born at the right moment. In the simulation plant wall design, you do not need to consider the geographical location and the restaurant light and other factors, only need to design a patchwork of different shapes plan wall depending the overall interior decoration style. After carefully coordination, the simulation plant wall can be spurious as genuine. Such like Xitang Sanxia Music Diner "Fig. 3", "Fig, 4", It is a music theme Grill restaurant with singer singing. It uses natural sense wood together with vertical greening in the overall decoration. The steel frame which has the isolation function has many potted plants on it and the whole background wall of the restaurant is a simulation plant wall. It uses green moss as ground, and decorated with weeds and other plants, coupled with the stone and the animal's head, illuminated by spotlights with strong visual impact, and brings people the rough and original feelings. 


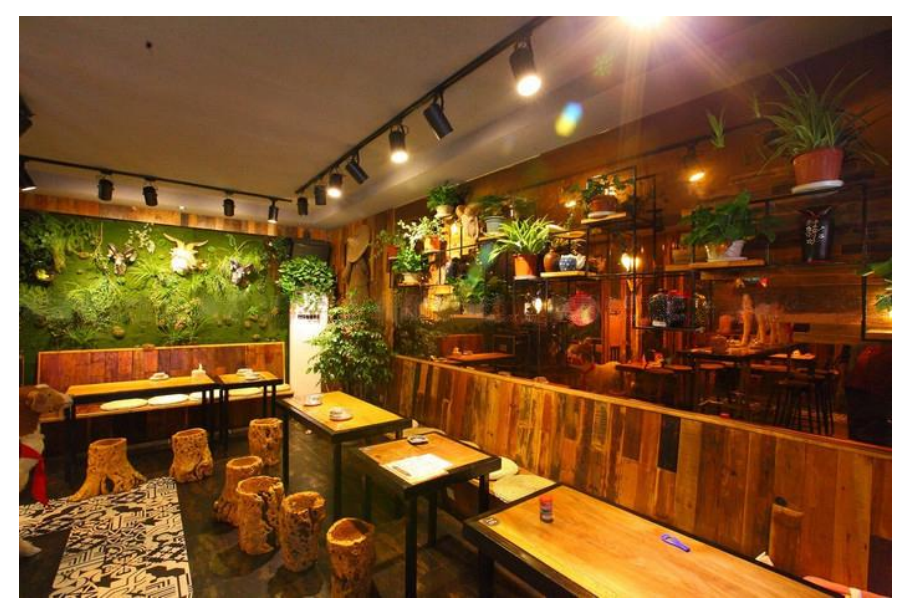

Fig. 3. Xitang Sanxia Music Diner

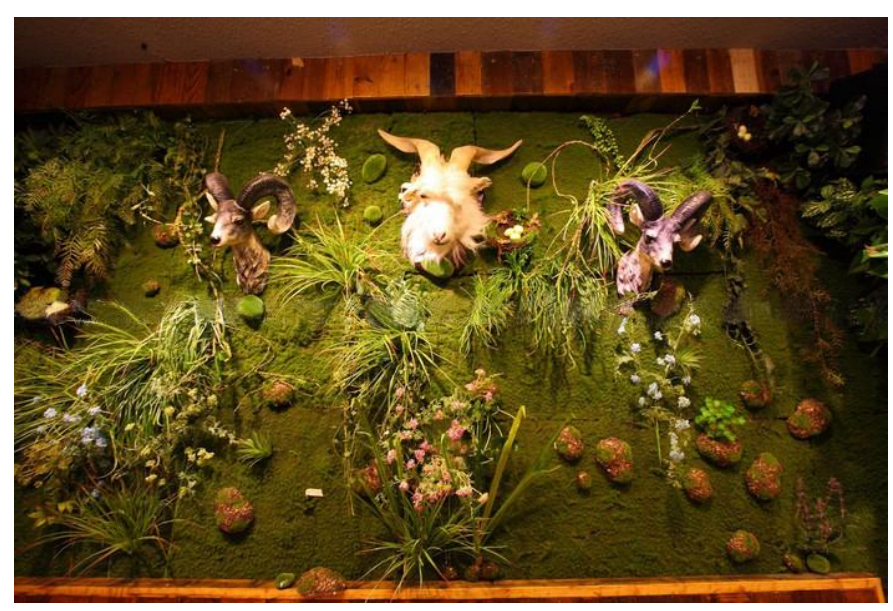

Fig. 4. Xitang Sanxia Music Diner

\section{CONCLUSION}

Under the big environment of advocating low-carbon environmental protection, the application of vertical greening in restaurant space is people's yearning for nature. Restaurant space is indispensable activity place for modern people, we dining in a restaurant is not only to eat, but we want to enjoy a high level overall perception from the sense of taste to visual. Vertical greening can increase the affinity of the restaurant, and beautify the overall environment. People in a busy city life can have a place for rest and reorganization.

\section{REFERENCES}

[1] Sun Xiaojiao, Analysis of indoor vertical greening [J]. Shanxi Architecture, 20115.

[2] Ren Xiaolin Design and Research on Felt Bag style interior decoration greening wall [D]. Northeast Forestry University, 2013.

[3] He Xiaobo. Evolution of vertical greening technology and design practice of plant curtain wall [D]. Zhejiang Agriculture and Forestry University, Master's thesis, 2013. 